\title{
Research and Application of Smart Hanger Based on Airbag Inflation Model and Fuzzy Self-adaptive PID Method
}

\author{
Yihong Zhang ${ }^{1,2, *}$, Xi Jin ${ }^{1}$ and Zhijie Wang ${ }^{1}$ \\ ${ }^{1}$ College of Information Science \&Technology, DongHua University, Shanghai 201620, China; \\ ${ }^{2}$ Engineering Research Center of Digitized Textile and Fashion Technology, Ministry of Education; \\ ${ }^{*}$ Corresponding author
}

\begin{abstract}
This paper demonstrates one smart hanger based on airbag inflation and fuzzy Self-adaptive PID method for intelligent garment inspecting system. To fully extend the garment to a proper position, one fuzzy Self-adaptive PID method is given to control the pneumatic motor by comparing the feedback value of the flexible pressure sensor with the threshold value. Flexible sensor arrays were embedded on the surface of the smart hanger; the pressure value detected shows appropriate degree between cloths and the smart hanger, and it's an important standard for garment inspection. The adaptive fuzzy control algorithm is proposed to control the whole process.
\end{abstract}

Keywords-smart hanger; garment defect detecting; flexible pressure sensor; adaptive fuzzy PID contro; airbag inflation model

\section{INTRODUCTION}

This An smart hanger model [1] based on graphite alkenes sensor and airbag inflation is presented in this paper, the smart hanger is usually applied for the garment defect detecting research area. Figure I illustrated the working theory diagram of the smart hanger.

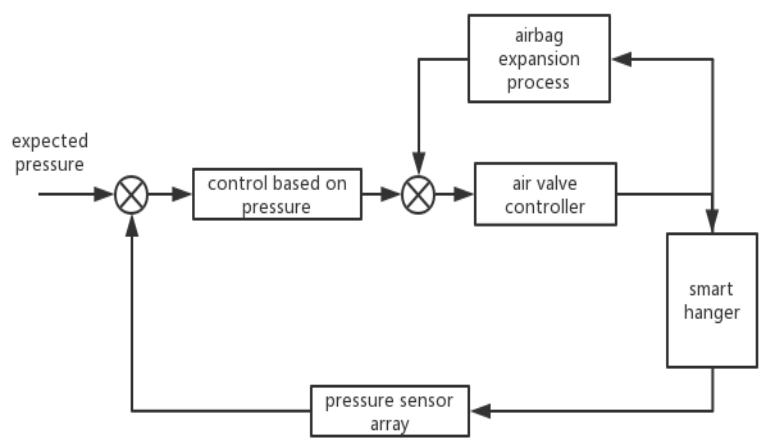

FIGURE I. WORKING THEORY DIAGRAM OF THE SMART HANGER

The clothing pressure [2][3]refers to the pressure caused by limits of clothing, garment shape, size, weight and other factors to the human body, or when loose amount of clothing is not adapted to the slipping amount of skin due to the stretching of the skin and needs the elastic extension of clothes to compensate. It is a factor which cannot be ignored in the garment defect detecting [4] [5] research area for image capturing [6]. In this paper, The pressure measurement of different parts needs to take advantage of sensor array consisting of multiple sensors, and the materials are flexible graphite alkenes pressure sensors[7] and airbag inflations[8][9] The flexible graphite alkenes pressure sensors are equipped with characteristics like flexibility, high sensitivity and so on, which made it very suitable for this study. Figure II illustrated the structure of airbag inflations and the parameter property flexible graphite alkenes pressure sensors.

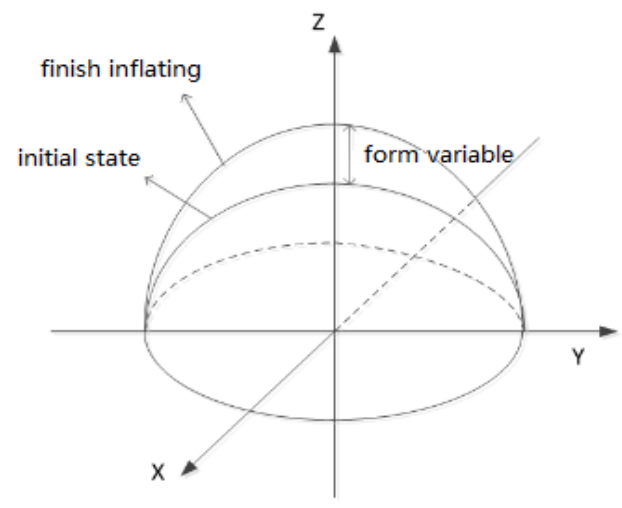

A

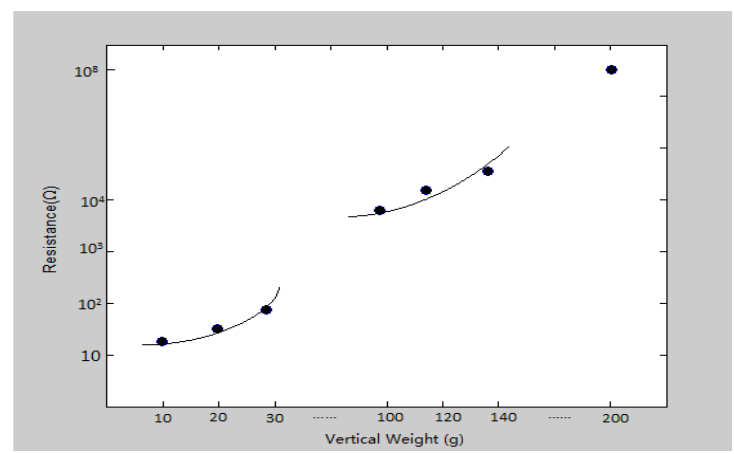

B

FIGURE II. A. THE STRUCTURE OF AIRBAG INFLATIONS AND B THE PARAMETER PROPERTY FLEXIBLE GRAPHITE ALKENES PRESSURE SENSORS 
TABLE I PIEZO ELECTRIC REACTION OF FLEXIBLE GRAPHITE ALKENES PRESSURE SENSORS

\begin{tabular}{|l|l|l|l|l|l|l|l|}
\hline Pressur $(\mathbf{N})$ & 0.01 & 0.02 & 0.03 & 0.1 & 0.12 & 0.14 & 0.2 \\
\hline $\begin{array}{l}\text { Resistence } \\
\text { value }(\boldsymbol{\Omega})\end{array}$ & 30 & 50 & 98 & 2034 & 5069 & 11543 & $\begin{array}{l}\text { Too } \\
\text { large }\end{array}$ \\
\hline
\end{tabular}

Table1 illustrates the piezoelectric reaction of flexible graphite alkenes pressure sensors.

The dynamic model of intelligent hanger and the parameters' self-tuning fuzzy control [10] strategy got tested and verified via experiment and simulation. In order to see the advantages of parameter self-adjusting fuzzy control [11][12], its simulated results were compared with those of the conventional PID simulation[13]. The comparison between models of parameter self-adjusting fuzzy control of clothes made of different materials can start from drifting, and repeatability, linearity and retardation and other factors. And then the plane measurement in stationary state and the curved surface measurement whose radius is greater than $32 \mathrm{~mm}$ would be conducted, from which different trends and results were accompanied by plane and curved surface measurement under different conditions of materials with different quality, so it is necessary to conduct a weight analysis on multiple target functions to get material parameter that meets as much targets as possible. Multi-object collaborative optimization algorithm [14] [15] is also proposed in this paper to achieve the optimal value relative for the different targets.

\section{FUZZY SELF-ADAPTIVE PID METHOD}

The parameter self-adaptive fuzzy control program was written in MATLAB according to the dynamic model. Its schematic diagram of parameter self-adaptive fuzzy control is shown in Figure 3, and the flow diagram of parameter selfadaptive fuzzy control is illustrated in Figure 4. According to the character of the smart hanger, self-adaptive fuzzy control object is defined as equation (1):

$$
\begin{aligned}
\Delta u(k) & =K_{p}[e(k)-e(k-1)]+K_{I} e(k)+K_{D}[e(k)-2 e(k-1)+e(k-2)] \\
& =K_{p} e_{c}(k)+K_{I} e(k)+K_{D}\left[e_{c}(k)-e_{c}(k-1)\right]
\end{aligned}
$$

And it is incremental pid, In the formula (1), e means deviation of force, $e_{c}$ means diviation change rate of force. $\mathrm{K}_{\mathrm{p}}, \mathrm{k}_{\mathrm{i}}, \mathrm{k}_{\mathrm{d}}$ are fuzzy logic tuing PID parameters with proper fuzzy rules relatively. Formulate the fuzzy inference rules based on membership function that are formulated by input and output. The rules descript in following form: if (e is *) and $\left(\mathrm{e}_{\mathrm{c}}\right.$ is $\left.*\right)$ then $\left(\mathrm{k}_{\mathrm{p}}\right.$ is $\left.*\right)\left(\mathrm{k}_{\mathrm{i}}\right.$ is $\left.*\right)\left(\mathrm{k}_{\mathrm{d}}\right.$ is $\left.*\right)$. Table II illustrates the input and output parameter of discourse domain. And Table III illustrated the fuzzy rule value of $\Delta \mathrm{k}_{\mathrm{p}}$, the fuzzy rule value of $\Delta \mathrm{k}_{\mathrm{i}}$ and $\Delta \mathrm{k}_{\mathrm{d}}$ will not be illustrates in this paper for the space limitation.

\begin{tabular}{|c|c|}
\hline Parameter & Discourse domain \\
\hline$e$ & {$[-0.3,0.3]$} \\
\hline$e_{c}$ & {$\left[\begin{array}{ll}-30, & 30]\end{array}\right.$} \\
\hline$\Delta k_{g}$ & {$[-0.2,0.2]$} \\
\hline$\Delta k_{I}$ & {$[-0.1,0.1]$} \\
\hline$\Delta k_{D}$ & {$\left[\begin{array}{ll}-3 e-4, & 3 e-4]\end{array}\right.$} \\
\hline
\end{tabular}

\section{TABLE II INPUT AND OUTPUT OF DISCOURSE DOMAIN}

TABLE III $\triangle \mathrm{k}_{\mathrm{p}}$ FUZZY RULE

\begin{tabular}{|c|c|c|c|c|c|c|c|}
\hline$e_{c}$ & NB & NM & NS & ZE & PS & PM & PB \\
\hline NB & PB & PB & PM & PM & PS & PS & ZE \\
\hline NM & PB & PB & PM & PM & PS & ZE & ZE \\
\hline NS & PM & PM & PM & PS & ZE & NS & NM \\
\hline ZE & PM & PS & PS & ZE & NS & NM & NM \\
\hline PS & PS & PS & ZE & NS & NS & NM & NM \\
\hline PM & ZE & ZE & NS & NM & NM & NM & NB \\
\hline PB & ZE & NS & NS & NM & NM & NB & NB \\
\hline
\end{tabular}

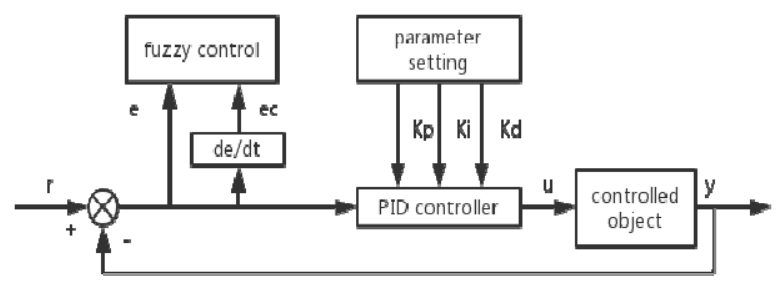

FIGURE III. THE SCHEMATIC DIAGRAM OF PARAMETER SELFADAPTIVE FUZZY CONTROL

Verifying the adjustment for control parameters of self-tuning fuzzy PID controller is the key. Figure IV shows changes of $k p$ parameter of self-tuning fuzzy PID controller, and it adjusts the change itself based on the output signals of fuzzy controller to achieve the stable control parameters. Figure V illustrated changes for language variables of self-tuning fuzzy PID controller, and it can be seen the language variables of selftuning fuzzy PID controller are symmetric to each other, which can make up of language variables of intelligent rack.

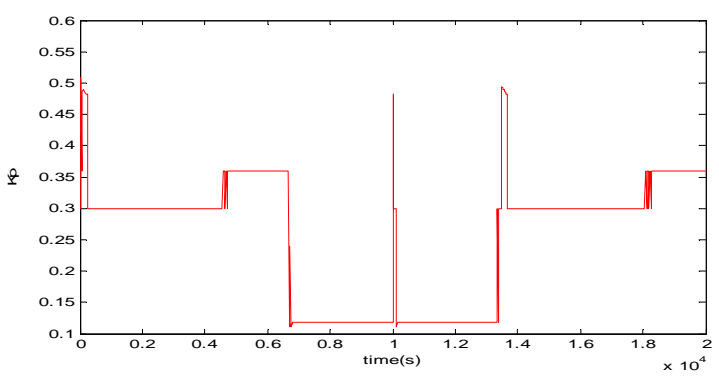

FIGURE IV. KP PARAMETER OF SELF-TUNING FUZZY PID CONTROLLER

Certification by the program above can prove that be the fuzzy control model based on parameters self-tuning can be applied to sensor design of intelligent hanger and designing it as controllers of the smart racks airbag is feasible. 


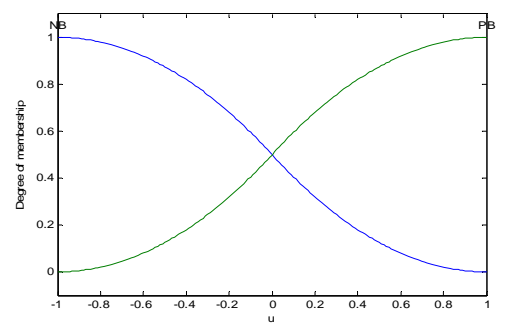

(a)

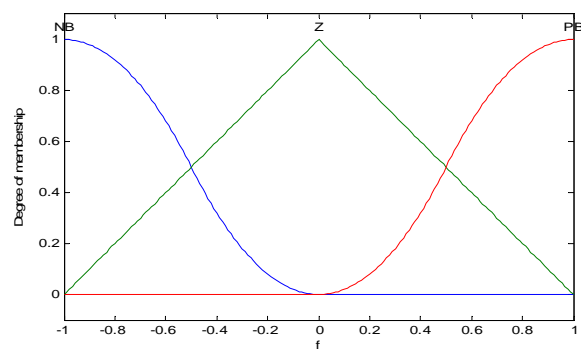

(b)

FIGURE V. CHANGES FOR LANGUAGE VARIABLES OF SELFTUNING FUZZY PID CONTROLLER

\section{SIMULATION AND EXPERIMENTAL RESEARCH ON NON- SENSOR NOISE CONTROL}

In this paper, the pressure define value is selected as the step input signal of the constant pneumatic system, and the system model is identified as the first order inertial plus pure delay system. The transfer function of the system is shown in equation 2 .

$$
T F=\frac{1}{7.8 s+1} e^{-2 s}
$$

Balloon cyst pressure sensor array in this article controls changes for air bags when servo motors inflate and deflate the air bags, and reflect the fit of clothing by making use of changes clothing pressure between clothes and air bags when air bags change. Motor realizes the whole inflated and deflated effect through a certain duty ration, as shown in Figure6.

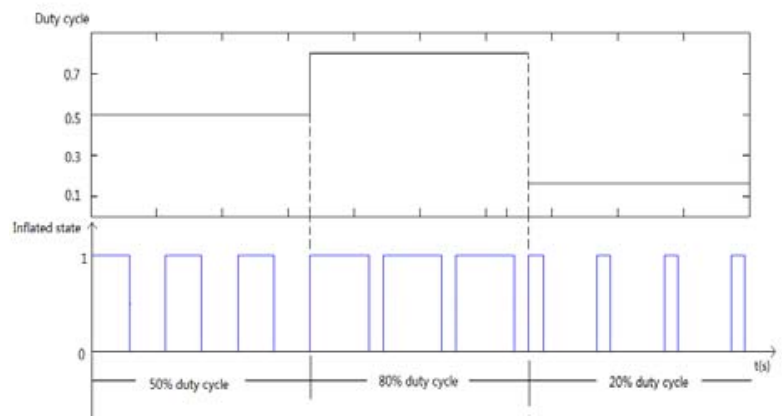

FIGURE VI. MOTORS RUNNING SKETCH MAP
The black string in the Figure displayed the enlargement of size of balloon, and blue line represents efficiency schematic with current duty ratio. 0.5 stands for that the inflating and deflating duty ration of balloon account for relatively $50 \%$, that is to say, inflatable efficiency is the same as deflating ones, with size of balloon invariable. 0.8 represents $80 \%$ of inflating and deflating duty ration, which means time for inflation is longer than time for deflation in a cycle, with balloon becoming larger. Airbag cannot both inflate and deflate, so adjusting the duty cycle is the way of inflating the balloon. This data can also be calculated from the control curves to see changing process of air bag at some point.

Before controlling the airbag of intelligent hanger, it is needed to discuss clothing comforts, which are expected value and setting value of airbag control. To take force on shoulder for cases, when hanging clothes on intelligent hanger and then buttoning them, in most cases, clothes will not completely fitting on hanger while immediately after hanging up clothes, and we need to inflate balloons on shoulder parts until clothes hanging on hanger do not expand any more. When recognizing this state, read out numbers through flexible pressure sensor array posted on balloons, and take it as expectation.

Take the shoulder as an example, $\mathrm{Rsh}=0.3 \mathrm{~N}$ is taken as expected value, which means the stable value that the system finally reaches. The input of PID control process is achieved through inflation and deflation of balloon. While the pressure of balloon increases, balloon is in inflatable state. It is mentioned in description for Figure 7 that the filling and deflating process of the balloon is achieved through adjustment of duty ratio. Because the balloon can neither only inflate nor deflating while inflating, time of inflation in a cycle is more than deflation in it. In general, it shows inflatable trend.

The measured parts in the paper include shoulder, chest and waist. Because sizes of different human parts are different, the shapes of hanger in these three parts are not the same. So before the control process, models of these three a parts are different. The same method was used to analyze and later correspondingly control parts beyond the shoulder, and differences can be seen from simulation process. Coupled with the different responses of different parts for clothing pressure, when discussing the comfort of clothing, the appropriate changes must be taken, such as steady-state value in this article of $0.3 \mathrm{~N}$ on the shoulder and waist $0.9 \mathrm{~N}$. For the pages limitation reason, experiments results conducted on arm and body part of smart hanger will not be proposed in this paper.

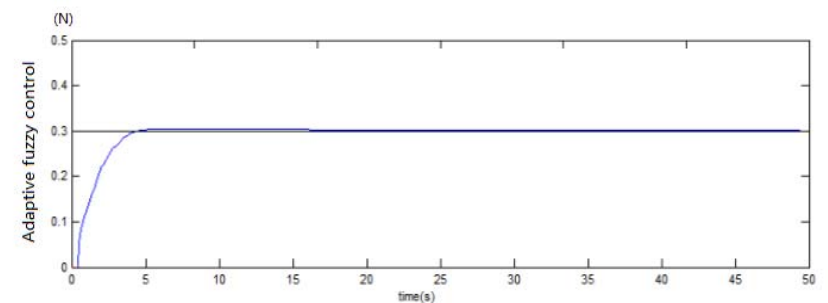

FIGURE VII. ARMS_FUZZY ADAPTIVE PID METHOD RESULTS

The Figure7 shows the control curve when making unclear adjustment to traditional PID. Compared with the conventional 
PID control, control process of fuzzy adjustment PID greatly reduces the amount of overshoot as well as the times of oscillation. In control process, rise time $t_{\mathrm{r}}$ presents the time required for reaching stable value for first time, peak time $t_{p}$ stands for the time the response curve needs to rise from 0 to the first peak, and maximum overshot refers to the difference between the maximum peak and steady-state value of response curve, generally written as percentages. The overshoot is only connected with damping ratio, and setting time $t_{s}$ refers to the time response curve needs to arrive and break within allowed error ranges (steady-state worth equals to $\pm 2 \%$ or $\pm 5 \%$, and \pm $5 \%$ is used in the paper). Comparing the traditional PID and fuzzy control PID, it can be found that after parameter selftuning control, difference between rising times is not very large, while peak time, overshoot and time for adjustment reduce significantly, which reflects the superiority of fuzzy control.

Intelligent hanger is designed for garments detection to detect the clothing pressure of garments with different materials. Due to differences in clothing materials in a balloon model, the parameters will change accordingly. In order to find out dynamic model and control the process effectively, extensive data collection is required so that dynamic models are more reliable.

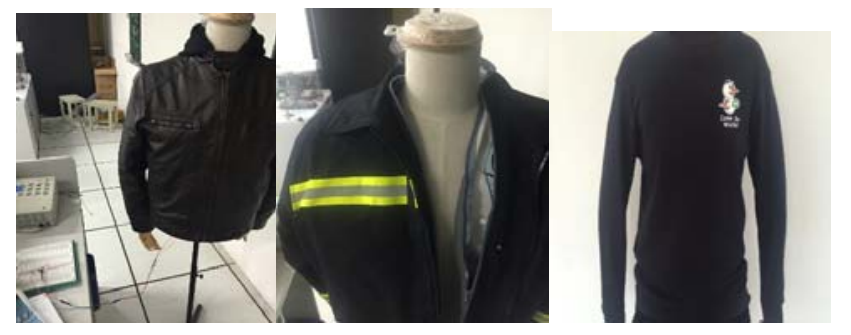

\section{FIGURE VIII. SIMULATION OF CLOTHES WITH DIFFERENT MATERIALS}

Through the simulation of clothing made of different materials in Figure9, the adaptability of fuzzy control PID controller was further verified. In sensors of parameters selftuning fuzzy control model above, verifying the garments of different materials can compare a number of different important parameters. Pressure value is set as $30 \mathrm{~g}$ and $20 \mathrm{~g}$, and the actuation duration is respectively $2 \mathrm{~min}$. When placing weights on the sensor, the sensor displays pressure values, and after $3 \mathrm{~min}$, it reaches a steady value. The degrees of stability are $96 \%$ and $93 \%$, and after $10 \mathrm{~min}$, it reaches $98 \%, 97 \%$. The stability has improved significantly over time. $30 \mathrm{~g}, 20 \mathrm{~g}$ and $10 \mathrm{G}$ were typed every $5 \mathrm{~min}$ following a descending order, with each input value repeating 20 times. According to test results, the mean and standard deviation were $25.65 \mathrm{~g} \pm 1.03 \mathrm{~g}, 0.48 \mathrm{~g} \pm$ $0.86 \mathrm{~g}$ and $7.28 \mathrm{G} \pm 0.48 \mathrm{~g}$ when the input values were $30 \mathrm{~g}, 20 \mathrm{G}$, and $10 \mathrm{G}$ respectively, and coefficient of variation 2.3, 3.2 and 6.6, showing that higher quality brought better repetition performance.

\section{IV.SUMMARY}

In this paper, experiments and simulations were conducted to verify the dynamic model of intelligent hanger based on control strategy of fuzzy self-adaptive PID. Meanwhile, the comparison between models of parameter self-adjusting unclear control of clothes made of different materials can start from drifting, and repeatability, linearity and retardation and other factors. It was found that the different trends and results were accompanied by plane and curved surface measurement under different conditions of materials with different quality, so it is necessary to conduct a weight analysis on multiple target functions to get material parameter that meets as much targets as possible. It could be concluded that fuzzy self-adaptive PID control method proposed in this paper is applicable and optimal for the smart hanger control in the garment defect detecting research area.

\section{ACKNOWLEDGMENT}

This research was financially supported by the ShangHai Science Foundation-"The Research and Application of Intelligent Garment Defect Detecting based on Cloud Computing", Funding Number: 14ZR1400400.

This research work was supported by the China Central University Foundation, Project Number: 15D110406

\section{REFERENCES}

[1] Y.H. Zhang, C.M.W Yuen, W.K Wong, et al. A Smart Hanger Model Based on 6-DOF Robot and PID Method for Garment Inspection System [J]. Lecture Notes in Electrical Engineering, 2012, 136:369-376.

[2] Y.Na Clothing pressure and physiological responses according to boning type of non-stretchable corsets[J]. Fibers and Polymers, 2015, 16(2):471478.

[3] Y.Liu, D .Chen, The influence of clothing pressure exerted by girdle on inhibition ability of young females[J]. International Journal of Clothing Science and Technology, 2016(5).

[4] Y .Zhang. Development of an intelligent inspection system for detecting and classifying garment defects[J]. Phytomedicine International Journal of Phytotherapy \& Phytopharmacology, 2013, 17(8-9):693-697.

[5] Lee C K H, Choy K L, Ho G T S, et al. A hybrid OLAP-association rule mining based quality management system for extracting defect patterns in the garment industry[J]. Expert Systems with Applications, 2013, 40(7):2435-2446.

[6] Kamino T, Tomimatsu T. Method for manufacturing image capturing device and image capturing device[J]. 2017.

[7] L. Wang. Pressure sensing material based on piezoresistivity of graphite sheet filled silicone rubber composite[J]. Sensors \& Actuators A Physical, 2016.

[8] D.E. Kim, Y.H. Joo, M.C. Kang. Performance evaluation of slim lowrisk-deployment dual-type passenger airbag system with dispersed inflation pressure $[\mathrm{J}]$. International Journal of Automotive Technology, 2016, 17(4):689-696.

[9] Cheng Han. Simulation study of airbag process [D]. Nanjing University of Aeronautics \& Astronautics, 2009.

[10] C.M. Cao, Z.M. Wu, L. Liang, et al. Design and experiment of double fuzzy control system for tea leaves machine [J]. proceedings of the Chinese society of agriculture and agriculture, 2016, 47 (7): 3-6.

[11] H.Q. Wu, Z. Su, Y.M. Shen. Design of adaptive fuzzy controller for nonlinear systems [J]. Electronic Science and technology, 2016, 29 (7): 36-39.

[12] Z. Chen, The application of fuzzy PID control strategy in automotive power steering system $[\mathrm{J}]$. electronic technology and software engineering, 2016 (12): 250-250.

[13] B.Perumal,M.Aramudhan, AMulti-Objective Fuzzy Ant Colony Optimization Algorithm for Virtual Machine Placement[J]. 2016, 5(4):165-191.

[14] D.J. Persis, T.P.Robert. Ant Based Multi-objective Routing Optimization in Mobile AD-HOC Network[J]. Indian Journal of Science \& Technology, 2015, 8(9):875. 